\title{
PENDEKATAN BIONOMI PADA PELUANG PENGEMBANGAN PERIKANAN TANGKAP DI KABUPATEN KEPULAUAN TALAUD
}

\author{
Bionomy Approach on Capture Fisheries Development Opportunity in Talaud \\ Islands Regency
}

Oleh:

\author{
Jeti Pulu1 ${ }^{*}$, Mulyono S. Baskoro², Daniel R. Monintja², Budhi H. Iskandar², \\ dan Akhmad Fauzi ${ }^{3}$ \\ 1 BAPPEDA Kabupaten Talaud \\ 2 Departemen Pemanfaatan Sumber Daya Perikanan, FPIK, IPB, Jl. Lingkar Kampus, Darmaga - Bogor 16680 \\ ${ }^{3}$ Departemen Ekonomi Sumber Daya dan Lingkungan, FEM, IPB, \\ Wing Rektorat lt. 3 Kampus IPB Darmaga - Bogor 16680 \\ *Korespondensi: jety_poeloe@yahoo.com
}

Diterima: 7 Juni 2010; Disetujui: 10 Oktober 2010

\begin{abstract}
The research is aimed to reveal opportunity development of the capture fisheries in Talaud Islands Regency by using bionomy approach with Gordon-Schaefer model (Fauzy, 2005) concerning the dominant of illegal fishing activities around the area. The research was started by collected some secondary data on fish production and number of fishing units. Primary data were collected on catch composition and types of fishing gear. Gordon-Schaefer methods was applied to evaluate the tuna and skipjack resources in the area. The troll and pole and line are indicated as the dominant fishing gears used to catch the skipjack and tuna. In case of open access condition, the production will end up to 25,09 tons, while the resource rent will be end up to zero. For the development, simulations were exercised in 3 scenarios: 1) scenario of enhancing domestic fleet, 2) scenario of illegal fishing, and 3) scenario of net surplus. With those scenarios, if the illegal fishing could be eliminated, the capture fisheries in this regency could render economic value to 10 billion rupiah.
\end{abstract}

Key words: capture fisheries, scenarios of development, Talaud Islands Regency

\section{ABSTRAK}

Tujuan penelitian ini adalah untuk mengkaji kemungkinan pengembangan perikanan tangkap di Kabupaten Kepulauan Talaud dengan pendekatan bionomi dengan model GordonSchaefer (Fauzy, 2005), mengingat kegiatan penangkapan ikan secara ilegal sangat dominan terjadi di kawasan pulau-pulau terluar ini. Penelitian didahului dengan pengumpulan data sekunder berupa statistik produksi perikanan dan diikuti dengan pengumpulan data primer tentang komposisi jenis dan jumlah alat tangkap yang digunakan. Pancing tonda dan huhate merupakan alat dominan yang digunakan untuk menangkap cakalang dan tuna. Pada kondisi open access produksi akhirnya hanya akan mencapai 25,09 ton dan rente sumber daya akan berakhir dengan nol rupiah artinya akan merugi. Simulasi untuk pengembangan, dilakukan dalam 3 skenario: 1) skenario peningkatan armada domestik, 2) skenario illegal fishing, dan 3) skenario net surplus. Melalui simulasi skenario tersebut, terungkap bahwa bila illegal fishing dapat dihindari, maka potensi perikanan tangkap di Kabupaten Kepulauan Talaud dapat menghasilkan nilai ekonomi sebesar 10 milyar rupiah.

Kata kunci: perikanan tangkap, skenario pengembangan, Kabupaten Kepulauan Talaud 


\section{PENDAHULUAN}

Kerjasama perbatasan Indonesia dan Filipina telah dirintis sejak 14 September 1965 melalui penanda tanganan Border Crossing Agreement hingga tercapainya Border Crossing Agreement 1975 (BAPPEDA Kab. Talaud, 2000). Berdasarkan persetujuan tersebut, maka penduduk perbatasan diberikan kemudahan untuk melakukan kunjungan yang bersifat sosial-budaya. Kerjasama ini telah diperbaharui beberapa kali, guna menyesuaikannya dengan situasi dan perkembangan keadaan di lapangan. Sementara itu, untuk kegiatan perdagangan di daerah perbatasan, kedua negara pada tahun 1971 telah menyepakati Border Trade Agreement. Pada kedua persetujuan tersebut, ditetapkan bahwa sebagian pulaupulau di Kabupaten Sangihe dan Kebupaten Talaud sebagai wilayah kerjasama perbatasan Indonesia dan Filipina. Selain itu, sesuai dengan kesepakatan lintas perbatasan ini maka ditetapkan 3 Border Crossing Station (BCS) di wilayah Indonesia (Miangas, Marore, Tarakan) dan 3 Border Station di wilayah Filipina (Tibanban, Batuganding, Bungau).

Kabupaten Kepulauan Talaud memiliki sumber daya alam yang potensial terutama sumber daya perikanan karena hampir seluruh Daerah Kabupaten Kepulauan Talaud merupakan daerah pantai. Kemudahan lintas batas yang diperbolehkan tersebut telah membuat banyak hasil laut dari Kabupaten Talaud dijual lebih banyak ke Philipina dibandingkan masuk ke Indonesia sendiri. Hal ini dapat dipahami karena jarak yang lebih dekat ke negara tetanga daripada ke Sulawesi dalam hal ini Bitung dan Manado. Di lain pihak banyak pula terjadi illegal fishing yang dilakukan oleh kapalkapal ikan asing masuk ke wilayah perairan Indonesia. Bertitik tolak dari kondisi tersebut maka dalam tulisan ini dibahas kemungkinan peluang pengembangan perikanan tangkap di Kabupaten Talaud. Tujuan dari penelitian ini adalah untuk mengkaji peluang pengembangan perikanan tangkap di Kabupaten Talaud.

\section{METODOLOGI PENELITIAN}

\section{Waktu dan Lokasi Penelitian}

Penelitian ini dilaksanakan selama 12 bulan, mulai bulan Januari sampai dengan Desember 2007. Lokasi penelitian di perairan Kabupaten Kepulauan Talaud.

\section{Pengumpulan Data}

Data yang dipergunakan dalam penelitian ini meliputi data primer dan data sekunder. Data primer yang diperlukan diperoleh dengan cara melakukan wawancara terhadap responden tertentu yang dinilai memilik pengetahuan tentang perikanan tangkap di Kabupaten Talaud (purposive sampling). Data sekunder urut waktu (time series) juga digunakan dan diperoleh dari instansi terkait.

\section{Pengolahan dan Anasilis data}

Pengolahan data dilakukan dengan statistik sederhana, selain itu juga dilakukan pengolahan berdasarkan model bionomi (Fauzi dan Suzy, 2005; Anna, 2005). Analisis data dilakukan dengan menginterpretasikan hasil perhitungan model tersebut. Disamping itu, analisis deskripsi juga dilakukan untuk menggambarkan kondisi perikanan tangkap di Kabupaten Talaud.

\section{HASIL DAN PEMBAHASAN}

Hasil standarisasi produksi didapatkan bahwa produksi jenis ikan tuna dan cakalang memiliki trend produksi tahun 2002-2007 yang berfluktuasi. Produksi tersebut berasal dari hasil tangkapan huhate dan pancing tonda. Pada tahun 2004 produksi mengalami lonjakan kenaikan yang tertinggi selama 5 tahun terakhir kenaikannya mencapai 4.878 ton, Setelah tahun tersebut terjadi penurunan produksi dan naik kembali di tahun 2007 (PUSRIPT-BRKP, 2003).

Hasil perhitungan menunjukkan bahwa produksi telah melebihi produksi lestari yang juga berarti bahwa produksi ikan tuna dan cakalang telah mengalami tangkap berlebih (over fishing). Namun demikian ada beberapa tahun yang produksi aktualnya tidak melebihi produksi lestari yaitu pada tahun 2003 dan 2004, dimana di tahun 2003 produksi aktual sebesar 38424,30 ton atau di bawah produksi lestari yang sebesar 57.902,04 ton dengan pendekatan fungsi Gompertz (Gulland, 1983 dan Pauly, 1983). Produksi aktual pada tahun 2004 sebesar 45.039,30 ton juga di bawah produksi lestari dari fungsi Gompertz yang sebesar 54.415,34 ton.

Berdasarkan Tabel 1 didapatkan bahwa pada kondisi sumber daya ikan saat MSY, effort sebanyak 1.556,22 trip dan produksi MSY sebesar 216,62 Ton, rente saat MSY sebesar Rp. 621,91 juta. Pada kondisi MEY, dimana untuk effort sebesar $1.305,48$ trip dan kondisi produksi sebanyak 210,99 ton dan rente saat MEY sebesar Rp. 645,73 juta. Pada kondisi open access diperoleh nilai effort sebesar 2.610,96 trip dan produksi sebanyak 117,11 ton dengan rente saat open access sebesar Rp 0 artinya bahwa nelayan akan terus menangkap ikan hingga tidak mendapatkan keuntungan. 
Tabel 1 Kondisi Sumber daya saat MSY,MEY dan OA

\begin{tabular}{lrrr}
\hline \multirow{2}{*}{ Keterangan } & \multicolumn{3}{c}{ Solusi Bioekonomik } \\
\cline { 2 - 4 } & MEY & Open Access & MSY \\
\hline effort (Trip) & $1.305,48$ & $2.610,96$ & $1.556,22$ \\
produksi (Ton) & 210,99 & 117,11 & 216,62 \\
TR (JT) & 893,77 & 496,08 & 917,59 \\
TC (JT) & 248,04 & 496,08 & 295,68 \\
rente (JT) & 645,73 & 0,00 & 621,91 \\
\hline
\end{tabular}

Sumber data diolah dari : Dinas Kelautan dan Perikanan Provinsi Sulawesi Utara.

\section{Analisis Kelayakan Usaha}

Berdasarkan analisis usaha, diketahui bahwa usaha perikanan tangkap di Kabupaten Kepulauan Talaud membutuhkan modal investasi antara Rp. 14.000.000 hingga 47.000.000 rupiah dan biaya yang paling tinggi pada alat tangkap pukat cincin. Besarnya biaya usaha, penerimaan, keuntungan, dan $\mathrm{R} / \mathrm{C}$ ratio dari setiap jenis teknologi penangkapan ikan di perairan Kabupatan Kepulauan Talaud disajikan pada Tabel 2.

Keuntungan usaha penangkapan ikan alat tangkap pancing tonda memberi keuntung- an yang tertinggi yaitu sebesar Rp. 10.587.300. Tingkat pendapatan $A B K$ yang paling tinggi ada pada jenis alat tangkap rawai hanyut, yaitu sebesar Rp. 5.010.000. Selanjutnya untuk nilai imbangan penerimaan biaya $(R / C)$ usaha penangkapan ikan di perairan Kabupaten Kepulauan Talaud, alat pancing tonda memiliki nilai $\mathrm{R} / \mathrm{C}$ yang tertinggi, yaitu sebesar 1,42 .

Berdasarkan perhitungan menunjukkan bahwa usaha penangkapan layak untuk dikembangkan. NPV yang diperoleh berkisar antara Rp. 456.000 sampai dengan Rp. 25.235.000, dimana alat tangkap yang memiliki NPV tertinggi adalah rawai hanyut.

Tabel 2. Nilai Kriteria Investasi Usaha Penangkapan (dalam Rp. 000)

\begin{tabular}{lcccc}
\hline \multirow{2}{*}{ Jenis Alat Tangkap } & \multicolumn{4}{c}{ Nilai Kriteria Investasi } \\
\cline { 2 - 5 } & NPV (Rp) & Net B/C & R/C & Kelayakan \\
\hline Pancing Tonda & 6.666 & 1,29 & 1,42 & Layak \\
Pancing Ulur & 456 & 1,02 & 1,12 & Layak \\
Rawal Hanyut & 25.235 & 1,84 & 1,36 & Layak \\
Jaring Insang & 11.722 & 1,45 & 1,23 & Layak \\
Pukat Cincin & 15.013 & 1,32 & 1,18 & Layak \\
\hline
\end{tabular}

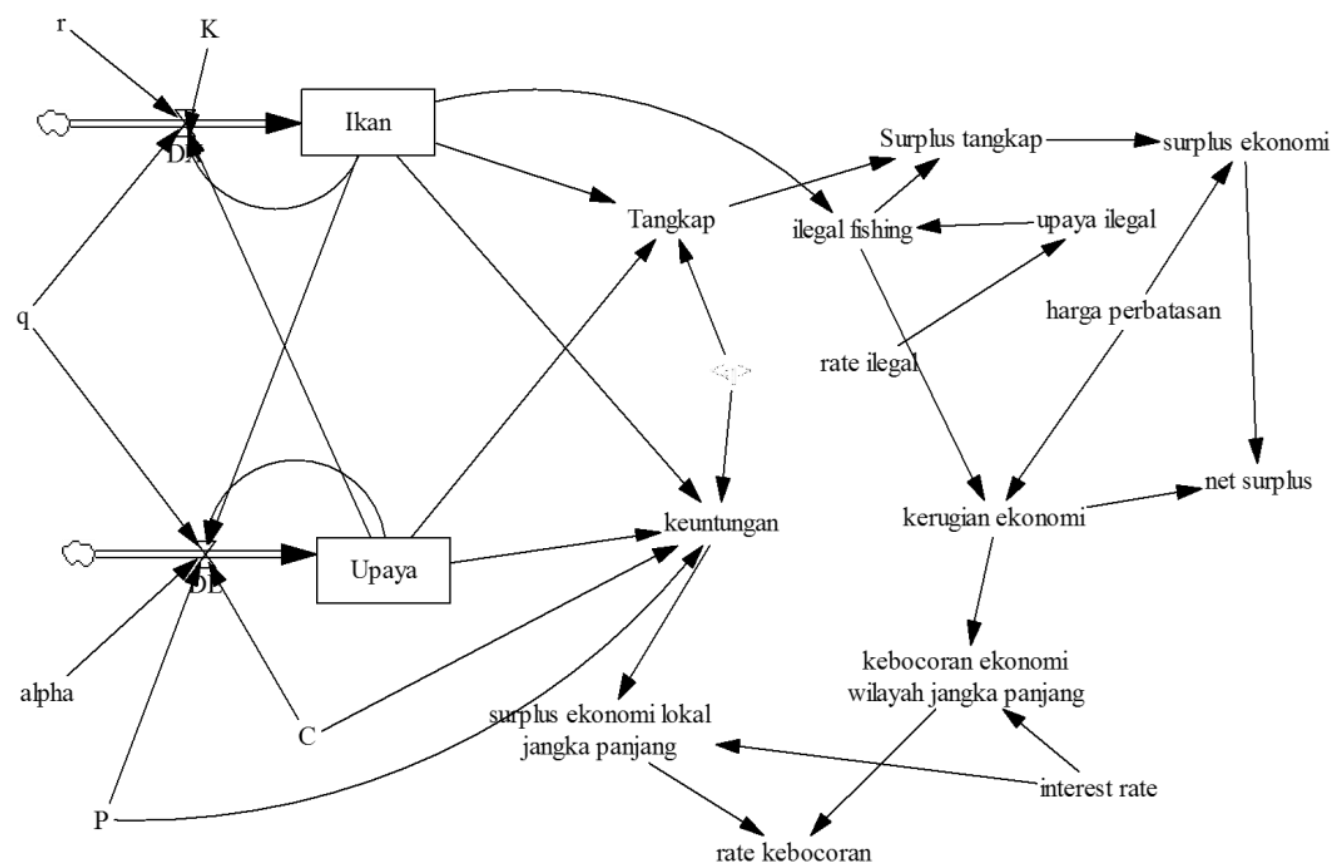

Gambar 1 Struktur simulasi. 


\section{Model Simulasi Penangkapan Perikanan Perbatasan}

Analisis simulasi pada penelitian ini dengan menggunakan software Vensim. Adapun struktur simulasi yang dilakukan seperti pada Gambar 1, interaksi stok dan effort yang diukur dari kapal yang beroperasi di wilayah Talaud tergambar di sebelah kiri gambar simulasi. Sementara di sebelah kanan menggambarkan variabel dan parameter yang terkait dengan wilayah perbatasan seperti harga ikan di wilayah perbatasan, illegal fishing dan surplus tangkap yang dapat diperoleh setelah dikurangi dengan illegal fishing.

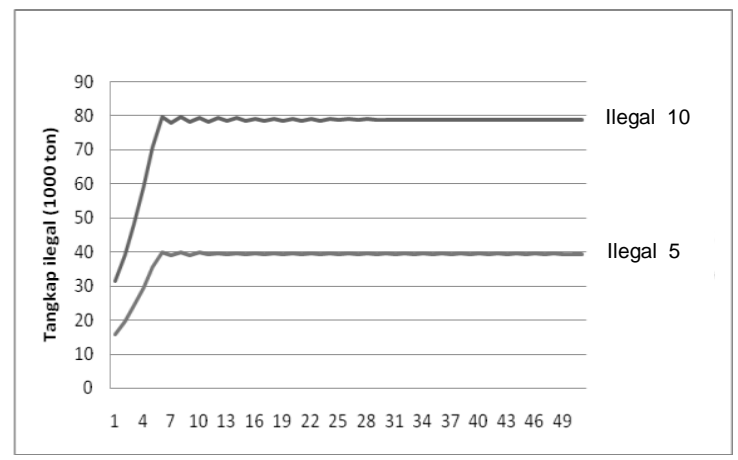

Gambar 2 Grafik skenario illegal fishing.

Hasil dari simulasi menunjukkan bahwa produksi perikanan yang dapat dilakukan oleh armada domestik Talaud mengalami peningkatan pada sepuluh tahun pertama dengan meningkatan yang tajam sampai mencapai lebih dari 30.000 ton. Dengan skenario illegal fishing sebesar $10 \%$ maka terjadi peningkatan yang tajam pada 10 tahun pertama yang kemudian mengalami stagnasi atau cenderung konstan setelah periode tahun kesepuluh (Gambar 2).

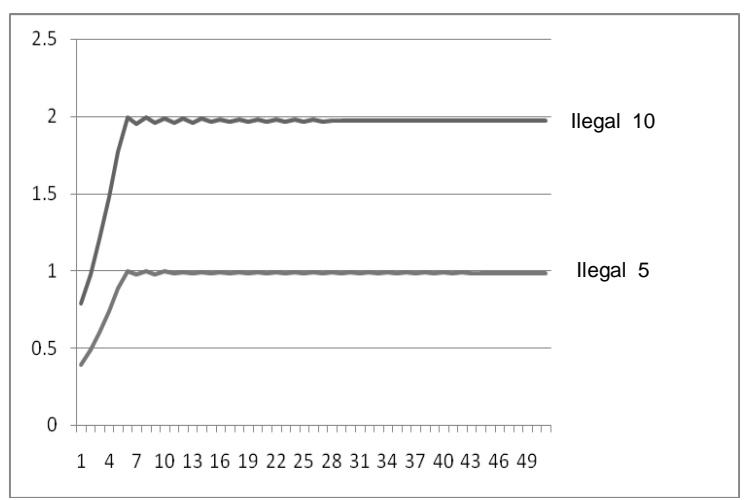

Gambar 3 Grafik tingkat kerugian.

Jumlah kapal di Talaud akan mengalami peningkatan dari sekitar rata-rata 500 kapal yang ada pada saat ini menjadi lebih dari 700 kapal di masa mendatang. Kerugian akibat illegal fishing berkisar antara Rp 1 milyar sampai Rp 2 milyar. Peningkatan kerugian ekonomi ter- jadi pada awal-awal periode 10 tahun pertama. $\mathrm{Hal}$ ini sejalan dengan tingkat terjadinya illegal fishing di wilayah Talaud yang cenderung meningkat pada periode awal. Kerugian ini kemudian cenderung constant pada periode selanjutnya pada kisaran $\mathrm{Rp} 2$ milyar untuk scenario illegal fishing 10\% dan sekitar Rp 1 milyar untuk kisaran illegal fishing 5 persen (Gambar 3).

Pada Gambar 4 net surplus1 menunjukkan surplus ekonomi jika tidak terjadi illegal fishing, sementara net surplus 2 menunjukan surplus yang terjadai pada rate illegal fishing $5 \%$ sementara net surplus 3 menunjukkan surplus ekonomi yang diperoleh ketika terjadi illegal fishing pada rate 10\%. Gambar 4 menunjukkan bahwa potensi ekonomi perikanan tangkap Talaud jika tidak terjadi illegal fishing mencapai lebih dari Rp 7 milyar bahkan terus meningkat mencapai hampir Rp 10 milyar, namun jika terjadi illegal fishing oleh kapalkapal perikanan dari Philipina, maka potensi ekonomi tersebut akan menurun hampir separuhnya. Sementara jika illegal fishing semakin marak dengan rate yang meningkat potensi ekonomi tersebut akan negatif pada tahun ke 20 yang tentu saja sudah pada taraf yang merugikan potensi perikanan Talaud itu sendiri.

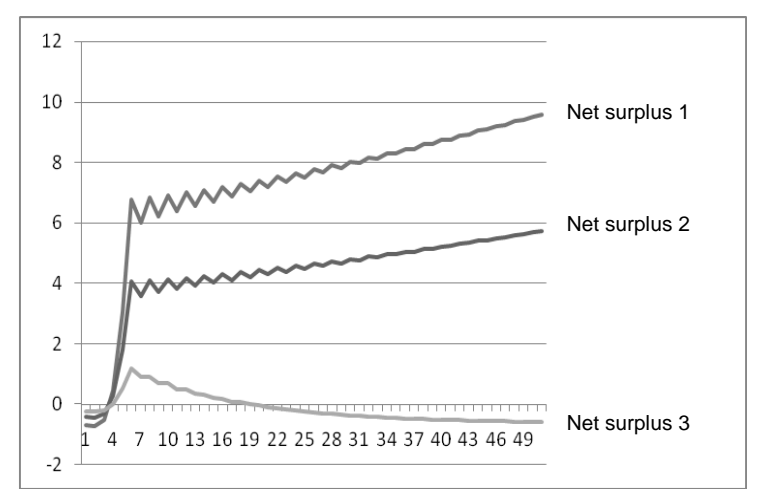

Gambar 4 Grafik Net Surplus Setiap Skenario.

Dari hasil analisis tersebut di atas maka peluang pengembangan perikanan tangkap di Kabupaten Talaud layak dan perlu dikembangkan dengan tujuan utama menekan laju illegal fishing. Penekanan laju illegal fishing ini dilakukan dengan kemudahan yang diberikan oleh pemerintah baik pusat maupun daerah dalam hal penyediaan sarana dan prasana perikanan tangkap. Salah satu hasil kajian dari Sylvia, G. 1992, menyebutkan bahwa dari sisi pengelolaan perikanan (fisheries management) kebijakan lokal sangat mempengaruhi iklim usaha. Selain kebijakan status perikanan tangkap dari sudut pandang skala usaha pun perlu diperhatikan. Kebijakan yang menjadi dasar pertimbangan pengembangan perikanan skal kecil tentunya akan berbeda dengan skala besar (Hermawan 
dkk, 2006). Perhatian pada skala kecil sebaiknya menjadi prioritas sebelum pengembangan skal besar. Oleh karena ini beberapa implikasi kebijakan yang perlu direkomendasikan diantaranya:

1) Melakukan restrukturisasi perizinan perikanan di wilayah Talaud. Restrukturisasi ini didasarkan atas perlunya untuk mendata seluruh input yang digunakan untuk mengekstraksi sumber daya perikanan serta output yang dihasilkan.

2) Pengembangan infrastuktur perikanan. Sebagai sebuah daerah terluar, fungsi infrastuktur perikanan dan kelautan sangat penting dalam mencegah terjadinya kebocoran ekonomi ke wilayah lain.

3) Kebijakan lain yang dapat ditempuh adalah mengembangkan kawasan ekonomi khusus melalui kerja sama bilateral maupun multilateral dengan negara tetangga seperti Philipina.

4) Kebijakan yang menyentuh langsung kepada masyarakat juga harus menjadi pertimbangan kebijakan pemerintah daerah. Program pemberdayaan masyarakat yang selama ini sedang dijalankan oleh pemerintah daerah dapat ditingkatkan dan lebih difokuskan pada peningkatan kemampuan ekonomi dan teknologi masyarakat dalam memanfaatkan sumber daya ikan di wilayah perairan yang lebih luas. Adapun kebijakan tersebut adalah:

a) Pertama, pengembangan sumber daya manusia di Talaud akan difokuskan dan diprioritaskan pada pendidikan kejuruan dan khususnya berbasis sumber daya lokal, terutama pada sumber daya laut.

b) Kedua, pemberdayaan masyarakat juga dilakukan melalui berbagai peningkatan kapasitas kelembagaan. Ini termasuk, penguatan pemerintahan tingkat desa, membangun otoritas perbatasan desa, mengembangkan sistem informasi desa (Infodes), pemberdayaan ekonomi produktif desa, program pemberdayaan perempuan, dan memperkuat kebijakan fiskal daerah.

c) Ketiga, di samping sumber daya manusia dan program pembangunan desa, pemberdayaan masyarakat di Talaud juga dilakukan dengan mendukung program transmigrasi nasional dari Nusa Tenggara Timur ke Talaud. Program ini juga didukung oleh program padat karya serta program keluarga berencana.
d)Keempat, dalam hal sektor pertanian, pemberdayaan masyarakat diarahkan untuk program ketahanan pangan, dan keragaman makanan serta petani mendirikan persatuan dalam masyarakat.

Sumber daya manusia menjadi fokus dalam hal ini karena kualitas sumber daya manusia merupakan unsur utama sebagai pengelola sumber daya alam. Kemampuan mengelola ini tentunya harus didasarkan pada pertim-bangan keberlanjutan sumber daya yang dikelolanya. Faktor sumber daya manusia ini menjadi penting sebagaimana dikemu-kakan oleh Monintja, 2003 yang menyebut-kan bahwa modal dasar pengembangan perikanan adalah kualitas sumber daya manusianya.

5) Selain beberapa kebijakan seperti yang telah disebutkan di atas, kebijakan yang tidak terkait langsung dengan perikanan namun sangat penting dalam menunjang kebocoran ekonomi adalah pengembangan ekonomi sektor-sektor penunjang seperti pariwisata bahari dan sektor pertanian.

6) Satu hal yang juga sangat penting dalam aspek kebijakan ini adalah menyangkut aspek legislasi. Pemerintah daerah Talaud dituntut untuk segera mengembangkan peraturan-peraturan daerah menyangkut pengelolaan sumber daya kelautan dengan mengakomodasi aturan-aturan non-formal (adat) yang telah ada dan berjalan di masyarakat. Sebagaimana disampaikan oleh Fauzy dan Buchari, 2002 bahwa kearifan lokal secara tidak langsung lebih menjamin keberlanjutan sumber daya perikanan. Hal lain yang juga perlu dipertimbangkan untuk dimasukkan dalam pertimbangan kebijakan pengembangan perikanan di Kabupaten Talaud adalah perikanan tangkap yang ramah lingkungan sebagaimana salah satu hasil kajian pengembangan sumber daya ikan cakalang dengan teknologi penangkapan ikan yang ramah lingkungan (Simbolon, 2004). Pendekatan pertimbangan tersebut adalah dengan memperhatikan stok dan keseimbangan pemanfaatannya.

Implikasi terhadap kebijakan ini tentunya akan menghadapi tantangan/kendala. Ada beberapa kendala yang dihadapi oleh pemerintah daerah untuk melaksanakan program, diantaranya.

1) Illegal fishing oleh kapal-kapal asing masih merajalela karena rendahnya pengawasan di daerah. Illegal fishing tidak hanya mengakibatkan kerugian ekonomi untuk wilayah 
itu juga memicu pasar gelap barang dari Filipina ke Talaud.

2) Masalah perbatasan dan otoritas tidak hanya terbatas antara Talaud dan Filipina, tetapi juga antara Talaud dan Sangihe Kabupaten tetangga. Sangihe Kabupaten ini sebelumnya "ibu" dari Talaud karena sebelumnya Talaud merupakan bagian dari Sangihe. Partisi empat pulau-pulau yang sekarang bagian dari Kabupaten Talaud (Marore, Matutuang, Mamanuk dan Ehise pulau-pulau) masih diperdebatkan antara Talaud dan Sangihe. Hal ini tentu saja akan menghambat pemberdayaan masyarakat lokal dan dapat upaya pembangunan.

3) Kendala lain yang perlu ditangani adalah masalah energi. Energi adalah mesin pertumbuhan ekonomi, terutama untuk wilayah pedalaman pulau-pulau kecil. Sayangnya, energi murah relatif langka di wilayah ini. Harga bahan bakar relatif lebih mahal di Talaud dibandingkan dengan yang di daratan Manado. Oleh karena itu, pemerintah harus membayar lebih mahal untuk menggerakkan perekonomian dibandingkan daerah lain atau kabupaten yang terletak di pedalaman. Demikian pula, nelayan harus membayar lebih mahal untuk membayar bahan bakar, sehingga biaya bahan bakar per $\mathrm{kg}$ ikan yang ditangkap relatif lebih mahal.

\section{KESIMPULAN DAN SARAN}

\section{Kesimpulan}

Berdasarkan hasil analisis, peluang pengembangan perikanan tangkap di Kabupaten Talaud dapat dilakukan. Hasil simulasi yang dilakukan mengindikasihkan produksi perikanan yang dapat diperoleh armada domestik Talaud mengalami peningkatan pada sepuluh tahun pertama dengan peningkatan yang tajam sampai mencapai lebih dari 30.000 ton. Produksi ini kemudian meski masih tetap mengalami peningkatan namun relatif stabil dengan tingkat peningkatan yang relatif tidak terlalu tajam.

Jumlah kapal di Kabupaten Talaud akan mengalami peningkatan dari sekitar rata-rata 500 kapal yang ada pada saat ini menjadi lebih dari 700 kapal di masa mendatang. Kerugian akibat illegal fishing berkisar antara Rp 1 milyar sampai Rp 2 milyar. Peningkatan kerugian ekonomi terjadi pada awal-awal periode 10 tahun pertama. Hal ini sejalan dengan tingkat terjadinya illegal fishing di wilayah Talaud yang cenderung meningkat pada periode awal. Kerugian ini kemudian cenderung konstan pada periode selanjutanya pada kisaran Rp 2 milyar untuk skenario illegal fishing $10 \%$ dan sekitar Rp 1 milyar untuk kisaran illegal fishing 5 persen. Potensi ekonomi perikanan Talaud jika tidak terjadi illegal fishing mencapai lebih dari Rp 7 milyar bahkan terus meningkat men-capai hampir Rp 10 milyar, namun jika terjadi illegal fishing oleh kapal-kapal perikanan dari Philipina, maka potensi ekonomi tersebut akan menurun hampir separuhnya. Sementara jika illegal fishing semakin marak dengan rate yang meningkat potensi ekonomi tersebut akan negative pada tahun ke 20 yang tentu saja sudah pada taraf yang merugikan potensi perikanan Talaud itu sendiri.

\section{DAFTAR PUSTAKA}

Anna, S. 2003. Model Embedded Dinamik Ekonomi Interaksi Perikanan-Pencemaran. Desertasi Sekolah Pasca Sarjana Institut Pertanian Bogor.

BAPPEDA Kabupaten Talaud. 2000. Border Crossing Agreement, 1975 dalam RENSTRA Kabupaten Talaud 2000 2004

Charles A.T and Reed, W.J. 1985. A Bioeconomic Analysis of Sequential Fisheries: Completion, Coexistence and Optimal Harvest Allocation between Inshore and Offshore Fleets. Canadian Journal of Fisheries and Aquatic Science Vol. 42.

Pauly D. 1983. Some Simple Methods fos Assesment of Tropical Fish Stock. FAO

Fauzi A dan Buchary E. 2002. A Socioeconomic Pespective of Environmental Degradation at Kepulauan Seribu National Marine Park, Indonesia. Journal of Coastal Management 30: 167-181.

Fauzi A dan Suzy A. 2005. Pendekatan Sumber daya Perikanan dan Kelautan untuk Analisis Kebijakan. Jakarta: Gramedia Pustaka Utama. 343 hal.

Gulland, J.A. 1983. Fish Stock Assessment: A Manual of Basic Methods. Wiley \& Sons. Rome. 223pp.

Hermawan M., M.F.A. Sondita, A. Fauzi, D.R. Monintja. 2006. Status Keberlanjutan Perikanan Tangkap Skala Kecil. Bulletin PSP Vol. XV. No. 2: 55. Departemen Pemanfaatan Sumber daya Perikanan. Fakultas Perikanan dan IImu Kelautan. IPB.

Monintja D.R. 2003. Strategi Pengembangan Sumber Daya Perikanan Tangkap Berbasis Ekonomi Kerakyatan. Seminar 
Nasional Strategi Pengembangan Sumber Daya Perikanan dan Kelautan Berbasis Kerakyatan. Riau, hal: 12.

PUSRIPT-BRKP (Pusat Riset Perikanan Tangkap, Badan Riset Kelautan dan Perikanan). 2003. Presiding Pengkajian Stok Ikan Laut di Perairan Indonesia. Jakarta: PURISPT-BRKP, Departemen Kelautan dan Perikanan, hal: 155hal.

Simbolon, D.F. 2004. Suatu Studi tentang Potensi Pengembangan Sumber Daya
Ikan Cakalang dan Teknologi Penangkapan yang Ramah Lingkungan. Bulletin PSP Vol XIII. No. 1: 4853. Departemen Pemanfaatan Sumber Daya Perikanan Fakultas Perikanan dan Ilmu Kelautan IPB Bogor

Sylvia, G. 1992. Concept in Fisheries Mangement: Interdiciplinary Gestalts and Socioeconomic Policy Models. Journal of Society and Natural Resources. Vol. 5: $116-133$ 